\title{
Growth Hormone Promotes Human T Cell Adhesion and Migration to Both Human and Murine Matrix Proteins In Vitro and Directly Promotes Xenogeneic Engraftment
}

\author{
Dennis D. Taub, * Galia Tsarfaty, ${ }^{5}$ Andrew R. Lloyd, ' Scott K. Durum," Dan L. Longo, ${ }^{5}$ and William J. Murphy \\ ${ }^{*}$ Clinical Services Program and ${ }^{\ddagger}$ Biological Carcinogenesis and Development Program, Program Resources, Inc./DynCorp, \\ Frederick, Maryland 21702-1201; "Laboratory of Leukocyte Biology and "Laboratory of Molecular Immunoregulation, Biological \\ Response Modifiers Program, Division of Cancer Treatment, National Cancer Institute-Frederick Cancer Research and Development \\ Center, Frederick, Maryland 21702-1201; and 'Department of Infectious Diseases, Prince Henry Hospital, Little Bay New South Wales, \\ Australia
}

\begin{abstract}
Recombinant human growth hormone (rhGH) promotes human $T$ cell engraftment in mice with severe combined immunodeficiency, suggesting that rhGH may have effects on $T$ cell adhesion and migration in vivo. The ability of rhGH to directly affect the adhesion capacity of human $T$ cells to a variety of human or murine adhesion molecules and extracellular matrix proteins was examined. rhGH induced significant human $T$ cell adherence to both human and murine substrates via either $\beta 1$ or $\beta 2$ integrin molecules. rhGH was capable of inducing significant migration of resting and activated human $T$ cells and their subsets. Most of the migratory response to rhGH was chemokinetic rather than chemotactic. In vivo engraftment studies in severe combined immunodeficiency mice receiving human $T$ cells revealed that treatment with rhGH resulted in improved thymic engraftment, whereas treatment with non-human-reactive ovine GH demonstrated no significant effects. These data demonstrate that rhGH directly augments human $T$ cell trafficking to peripheral murine lymphoid tissues. rhGH appears to be capable of directly altering the adhesive and migratory capacity of human $T$ cells to molecules of either murine or human origin. Therefore, GH may, under either isogeneic or xenogeneic conditions, play a role in normal lymphocyte recirculation. (J. Clin. Invest. 1994. 94:293-300.) Key words: chemokines • human severe combined immunodeficiency chimeras • trafficking - lymphocyte migration • neuroendocrine immune effects
\end{abstract}

Address correspondence to Dennis D. Taub, Ph.D., Clinical Services Program, Program Resources, Inc./DynCorp, NCI-FCRDC, Building 560, Room 31-19, Frederick, MD 21702-1201.

The content of this publication does not necessarily reflect the views or policies of the Department of Health and Human Services, nor does mention of trade names, commercial products, or organization imply endorsement by the U.S. Government. Care was provided in accordance with the procedures outlined in the Guide for the Care and Use of Laboratory Animals (National Institutes of Health Publication 86-23, 1985).

Received for publication 27 October 1993 and in revised form 4 February 1994.

The Journal of Clinical Investigation, Inc.

Volume 94, July 1994, 293-300

\section{Introduction}

Growth hormone $(\mathrm{GH})^{1}$ is a polypeptide of 191 amino acids produced by acidophilic cells in the anterior pituitary and serves as the major regulator in the promotion of cell growth and development of a variety of cell types (1). GH exerts its growthpromoting effects either directly or as a result of secondary mediators such as IGF-I, which is produced in response to GH in the liver (2). Although primarily known for its metabolic and neuroendocrine effects, $\mathrm{GH}$ has also been demonstrated to influence immune system development and function (3). Several in vitro and in vivo studies have demonstrated that $\mathrm{GH}$ can affect $T$ lymphocyte function $(4,5)$ and promote $T$ cell development in thymus (6).

Recombinant human GH (rhGH) has been shown recently to promote peripheral human $\mathrm{T}$ cell engraftment in mice with severe combined immune deficiency (SCID) $(7,8)$. These results suggested that GH may affect $\mathrm{T}$ cell migration and trafficking in vivo. However, no direct evidence demonstrating an effect of GH on T lymphocyte homing or migration has been reported. In this study, we examine the effects of rhGH on $\mathrm{T}$ cell adhesion and chemotaxis in vitro as well as its ability to directly promote the engraftment of human $T$ cells in SCID mice. The results presented here suggest that rhGH directly promotes $\mathrm{T}$ cell adhesion to and migration on a variety of adhesion and matrix molecules and may play a role in the selective trafficking of $\mathrm{T}$ cells in vivo.

\section{Methods}

Mice. C.B-17 scid/scid (SCID) mice were obtained from the Animal Production Facility at the National Cancer Institute-Frederick Cancer Research and Development Center (Frederick, MD). Mice were used at 8-12 wk of age and were kept under specific pathogen-free conditions. SCID mice were housed in microisolator cages, and all water, food, and bedding were autoclaved before use. SCID mice received 40 $\mathrm{mg}$ trimethoprim and $200 \mathrm{mg}$ sulfamethoxazole per $320 \mathrm{ml}$ of drinking water.

Transfer of human cells into SCID mice and treatment with GH. Human peripheral blood lymphocytes (huPBL) were obtained from healthy normal donors who had provided informed consent. huPBL were

1. Abbreviations used in this paper: GH, growth hormone; huPBL, human PBL; ICAM-1, intercellular adhesion molecule-1; MIP-1 $\beta$, macrophage inflammatory protein- $\beta$; ovGH, ovine growth hormone; rhGH, recombinant human growth hormone; SCID, severe combined immune deficiency; VCAM-1, vascular adhesion molecule-1. 
purified by counter-current elutriation (6). The lymphocyte fractions containing $>90 \%$ lymphocytes were used for transplantation into SCID recipients. The huPBL $\left(1 \times 10^{8}\right)$ were injected intraperitoneally into recipient SCID mice. All mice received $20 \mu \mathrm{l}$ of anti-asialo GM1 (Wako Chemicals, Dallas, TX) intravenously $1 \mathrm{~d}$ before huPBL injection, previously shown to improve human cell engraftment in SCID mice (9). SCID recipients received either $10 \mu \mathrm{g}$ rhGH (Genentech Inc., South San Francisco, CA), ovine GH (ovGH; provided by the National Institute of Diabetes and Digestive and Kidney Diseases, the Center for Population Research of the National Institute of Child Health and Human Development, and the Agricultural Research Service of the U.S. Department of Agriculture, as well as the University of Maryland School of Medicine, Baltimore, MD) in $200 \mu \mathrm{l}$ of HBSS, or HBSS alone intraperitoneally every other day until time of assay 6-10 wk later.

In certain experiments, PBLs were incubated with rhGH ( $10 \mathrm{ng} /$ $\mathrm{ml}$ ) overnight in the presence or absence of anti-human CD18 (IOT18) and anti-human CD29 (IOT29; Amac, Inc., Westbrook, ME) antibodies (each at $10 \mu \mathrm{g} / \mathrm{ml}$ ). After incubation, the PBLs were washed extensively and injected intraperitoneally into SCID mice. After $72 \mathrm{~h}$, the thymuses of these mice were harvested and tested by flow cytometry for the presence of human $\mathrm{T}$ cells.

Flow cytometric analysis. The following anti-human mAbs were used: HLA-ABC fluorescein isothiocyanate was purchased from Olympus Immunochemicals (Lake Success, NY); CD4 (Leu3a-fluorescein isothiocyanate), CD8 (Leu2a-biotinylated), and CD3 (Leu4-biotinylated) were purchased from Becton Dickinson and Co. (Mountain View, CA). Antibodies were used to label single-cell suspensions of thymocytes. Labeling was done in the presence of $2 \%$ human $A B$ serum (GIBCO/BRL, Grand Island, NY) to saturate human and mouse Fc receptors. After primary antibody incubation, cells were washed, fixed with $1 \%$ paraformaldehyde, and analyzed using an EPICS flow cytometer. Experiments were done at least six times with two or three mice per group. Statistics were done by comparing the occurrence and extent of engraftment with parametric analysis and Student's $t$ test.

$T$ cell adhesion assay. 96-well plates were coated in PBS with purified fibronectin at $500 \mathrm{ng} /$ well or with purified human intercellular adhesion molecule-1 (ICAM-1; generously donated by Dr. Timothy Springer, Harvard Medical School, Boston, MA) or vascular adhesion molecule-1 (VCAM-1; generously donated by Dr. Walter Newman, Leukon, Inc., Boston, MA) at 25-50 ng/well. Plates were coated overnight at $4^{\circ} \mathrm{C}$. Subsequently, plates were decanted, blocked with a $3 \%$ BSA solution, and then washed with RPMI 1640 containing $0.5 \%$ FCS. T cells were purified from the huPBL preparations using standard purification procedures (10). Some T cells were activated for 6-8 h on anti-CD3 antibody-coated plates as described previously (10). The T cells (typically $>94 \%$ pure) were labeled with chromium-51 for 1 $\mathrm{h}$ at $37^{\circ} \mathrm{C}$ and then washed. Labeled T cells $\left(2 \times 10^{5}\right.$ cells/well $)$ were applied to each well along with various concentrations ( $\mathrm{vol} / \mathrm{vol})$ of rhGH or PMA. The outer wells on the 96-well plate were not used, as washing these wells tends to lead to variability. Plates were incubated at $37^{\circ} \mathrm{C}$ for as short as $0.5 \mathrm{~h}$ with noticeable adhesion. Standard incubation was $1 \mathrm{~h}$. Plates were washed $(3 \times)$ with wide-mouthed yellow tips very gently by a swift forceful shake to remove wash liquid. To assure accurate and unbiased washing, washes were performed in three different directions. After the final wash, plates were patted dry on absorbent paper. $100 \mu \mathrm{l}$ of $1 \% \mathrm{NaOH}$ was placed into each well to lyse adherent $\mathrm{T}$ cells, and $50 \mu \mathrm{l}$ of the lysed cells was counted on a gamma counter.

$T$ cell chemotaxis. $T$ cell migration was quantitated by a modification of a Boyden chamber technique described previously (11). Briefly, T cells were suspended at $1 \times 10^{6}$ cells $/ \mathrm{ml}$ in RPMI 1640 plus $0.5 \%$ BSA and were placed in the top wells of a 48-well microchemotaxis chamber. The upper and lower wells were separated by a 5- $\mu \mathrm{m}$ pore polycarbonate filter which separated the cells from the control and experimental samples, consisting of rhGH or rhRANTES, in the bottom wells. All polycarbonate filters used in these experiments were coated with either collagen type IV or fibronectin
(GIBCO/BRL) $\sim 24 \mathrm{~h}$ before use in the assay (11). The chambers were incubated for $3 \mathrm{~h}$ at $37^{\circ} \mathrm{C}$ in a $5 \% \mathrm{CO}_{2}$ moist atmosphere, and the filters were then fixed, stained, and mounted by routine histological methods. Cell movement was quantitated by counting the total number of cells migrating completely through the matrix-coated filter in five high power fields in triplicate samples. Chemokinesis was assessed using a checkerboard analysis to distinguish directional migration (chemotaxis) from random migration (chemokinesis). The data are expressed as the number of countable cells per high power field; however, since there was variable aggregation of migrating cells, this probably represents a substantial underestimation of the total number of cells that have migrated into or through the filter.

\section{Results}

rhGH directly augments human $T$ cell adhesion to purified ICAM-1, VCAM-1, and fibronectin. Previous results from our laboratory have suggested that rhGH treatment of huPBL-SCID mice promotes human $T$ cell engraftment in the thymus of SCID mice, suggesting a potential role for rhGH in human $\mathrm{T}$ cell adhesion and trafficking into tissues $(7,8)$. To test this hypothesis, human $\mathrm{T}$ cells and rhGH were tested in a standard adhesion assay using both human and murine adhesion molecules. Resting and anti-CD3-activated $\mathrm{T}$ cells were labeled with chromium-51 and incubated with various doses of rhGH or PMA for 1 h on fibronectin-, ICAM-1 - , or VCAM-1 - coated plates. After incubation, nonadherent cells were removed, and the percentage of adherent $\mathrm{T}$ cells was quantitated. The results in Fig. 1 show that rhGH is capable of significantly augmenting both resting and activated human $\mathrm{T}$ cell adhesion to immobilized human ICAM-1, VCAM-1, and fibronectin. These adhesive effects occurred over a narrow concentration range of rhGH (10-100 $\mathrm{ng} / \mathrm{ml}$ ). It was also of interest to examine the effects of rhGH on the ability of human $T$ cells to bind to the mouse substrate ICAM-1. As above, human T cells were incubated in the presence of an optimal dose of rhGH versus PMA for $1 \mathrm{~h}$ on a human or murine ICAM-1-coated plate. The results in Fig. 2 show that human $T$ cells bind to both immobilized human and mouse ICAM-1 after incubation with rhGH, suggesting that rhGH may be exerting its in vivo effects on human $\mathrm{T}$ cells in the chimeric SCID model through the use of similar adhesion molecules. Although not shown, similar effects of rhGH inducing human $\mathrm{T}$ cell adhesion were also observed on mouse collagen type IV (data not shown). Subset analysis of the $\mathrm{T}$ cell population responding to $\mathrm{rhGH}$ revealed that both $\mathrm{CD}^{+}$and $\mathrm{CD}^{+} \mathrm{T}$ cells adhere in combination with optimal doses of rhGH (data not shown). This lack of subset specificity was observed with all substrates.

These results suggest that rhGH may directly induce the cell-surface expression of adhesion molecules that permit $\mathrm{T}$ cell adhesion and homing into various lymphoid organs. However, studies performed using purified human $\mathrm{T}$ cells treated with rhGH for $30 \mathrm{~min}$ or $24 \mathrm{~h}$ revealed no significant alterations in the cell-surface expression of many of the known adhesion molecules, including CD4, CD8, CD11a, CD11b, CD11c, LFA-1, VLA-2, VLA-4, VLA-5, VLA-6, CD18, CD29, ICAM-1, VCAM-1, or ELAM-1 (data not shown). These results suggest that rhGH may augment human $\mathrm{T}$ cell adhesion by possibly altering the affinity of expressed adhesion molecules for their respective ligands.

Additional analysis of the surface adhesion receptors involved in this GH-induced adhesion revealed, through a series 

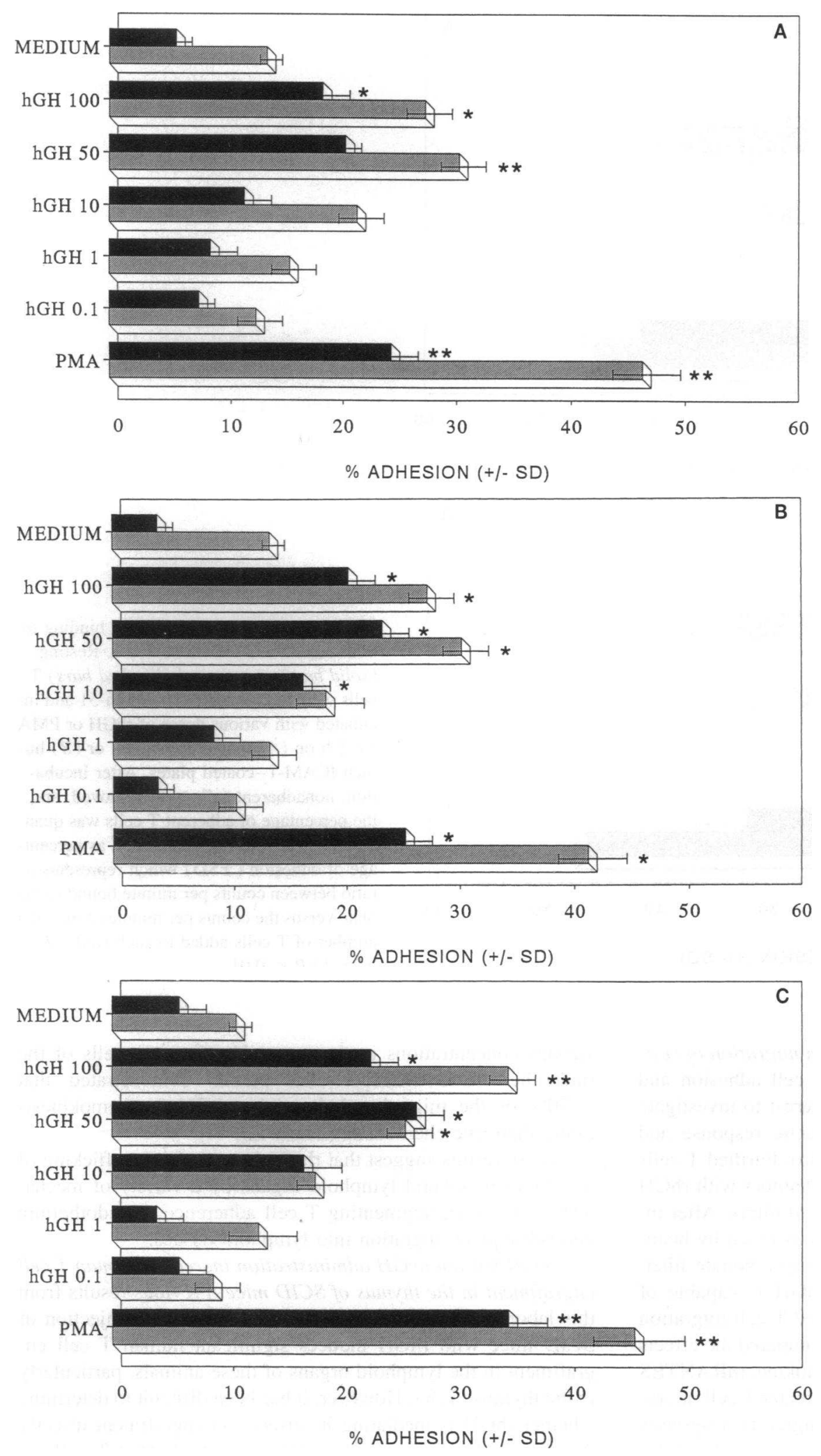

Figure 1. rhGH directly augments human $\mathrm{T}$ adhesion to purified ICAM-1, VCAM-1, and fibronectin. T cells, either resting (filled bars) or activated (hatched bars) with anti-CD3, were labeled with chromium-51 and incubated with various doses of rhGH or PMA for $1 \mathrm{~h}$ on $(A)$ ICAM-1 -, $(B)$ VCAM-1-, or $(C)$ fibronectin-coated plates. After incubation, nonadherent cells were removed, and the percentage of adherent $T$ cells was quantitated. The results are expressed as percentage of adhesion $( \pm S D)$ which represents a ratio between counts per minute bound to the plate versus the counts per minute of the total number of $\mathrm{T}$ cells added to each well. ${ }^{*} P<$ $0.05, * * P<0.01$. of antibody blocking studies, that the $\beta 2$ and $\beta 1$ integrin molecules are involved in the binding to the substrates ICAM-1 and VCAM-1/fibronectin, respectively (Fig. 3). Although a direct change in the affinity of these receptors for their substrates has not been measured, the data suggest that rhGH is capable of augmenting $\mathrm{T}$ cell adherence to various adhesion proteins and that this may be the mechanism by which rhGH promotes human $T$ cell peripheral engraftment in the SCID recipients. 

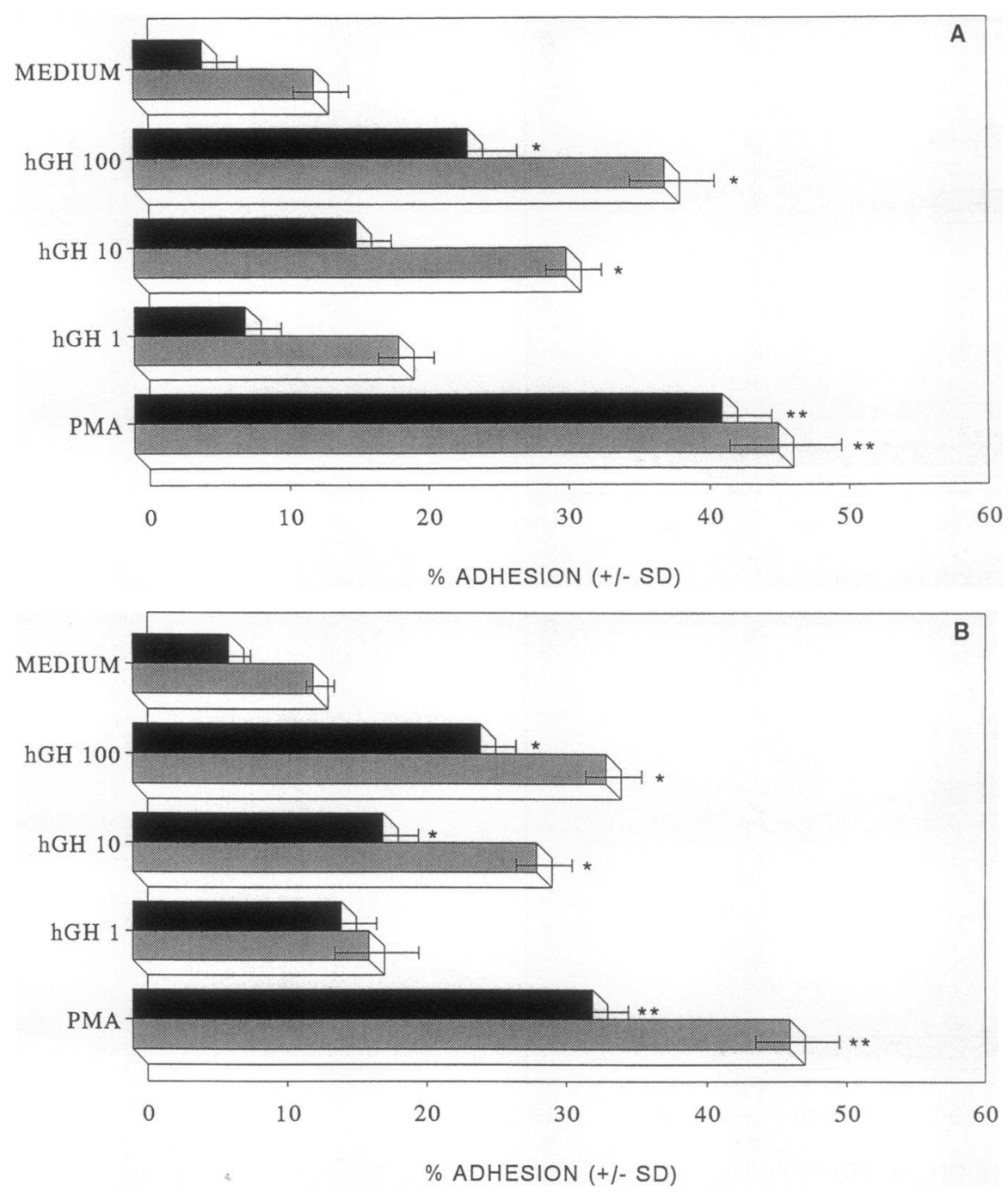

Figure 2. rhGH augments $\mathrm{T}$ cell binding to both human and mouse ICAM-1. Resting (solid bars) or activated (hatched bars) $\mathrm{T}$ cells were labeled with chromium-51 and incubated with various doses of rhGH or PMA for $1 \mathrm{~h}$ on $(A)$ mouse ICAM-1 - or $(B) \mathrm{hu}$ man ICAM-1-coated plates. After incubation, nonadherent cells were removed, and the percentage of adherent $T$ cells was quantitated. The results are expressed as percentage of adhesion $( \pm S D)$ which represents a ratio between counts per minute bound to the plate versus the counts per minute of the total number of $\mathrm{T}$ cells added to each well. $* P<$ $0.05, * * P<0.01$
rhGH induces an increase in the random migration of resting and activated human $T$ cells. Since $T$ cell adhesion and migration are interrelated, it was also of interest to investigate the ability of rhGH to mediate a chemotactic response and induce the directional $\mathrm{T}$ cell migration in vitro. Purified $\mathrm{T}$ cells were placed in a 48-well microchemotaxis chamber with rhGH at various concentrations on fibronectin-coated filters. After incubation, the number of migrating cells was assessed by histological examination of this matrix-coated polycarbonate filter. The results in Table I demonstrate that rhGH is capable of inducing both resting and anti-CD3-activated $\mathrm{T}$ cell migration at the dose range of $0.1-1 \mu \mathrm{g} / \mathrm{ml}$. We also compared the effects of rhGH on $\mathrm{T}$ cell migration with a beta chemokine, rhRANTES $(10,11)$. rhRANTES induced significantly greater T cell migration with 100 -fold less protein. Similar migratory responses were observed with another $\beta$ chemokine, macrophage inflammatory protein-1 $\beta$ (MIP-1 $\beta$ ) (10). In addition, similar migratory responses were observed on mouse collagen type IVand laminin-coated filters (data not shown). In an effort to determine whether rhGH is inducing the directional migration (chemotaxis) or random migration (chemokinesis) of human $\mathrm{T}$ cells, a checkerboard analysis was performed using rhGH at various concentrations in the top and/or bottom wells of the microchemotaxis chamber. The results demonstrated that $>50 \%$ of the migration induced by rhGH is chemokinesis rather than true chemotaxis (Table II).

These results suggest that rhGH may promote trafficking of $\mathrm{T}$ cells to peripheral lymphoid organs by a variety of mechanisms, including augmenting $\mathrm{T}$ cell adherence to endothelium and subsequent migration into lymphoid tissues.

rhGH but not ovGH administration increased human $T$ cell engraftment in the thymus of SCID mice. Previous results from this laboratory have demonstrated that continuous injection of SCID mice with rhGH induces significant human $T$ cell engraftment in the lymphoid organs of these animals, particularly in the thymus $(7,8)$. However, it has been difficult to determine whether rhGH is mediating its effects on engraftment directly through the binding of $\mathrm{GH}$ receptors on the human $\mathrm{T}$ cells or by binding murine $\mathrm{GH}$ receptors present on various murine cells in the SCID recipient. In an effort to distinguish between these two possibilities, we have tested ovGH for its effects on human $\mathrm{T}$ cell engraftment in the murine thymus. While ovGH cannot bind human $\mathrm{T}$ cells through their $\mathrm{GH}$ receptors, it can affect murine cells through their $\mathrm{GH}$ receptors $(6,12)$. Mice were 

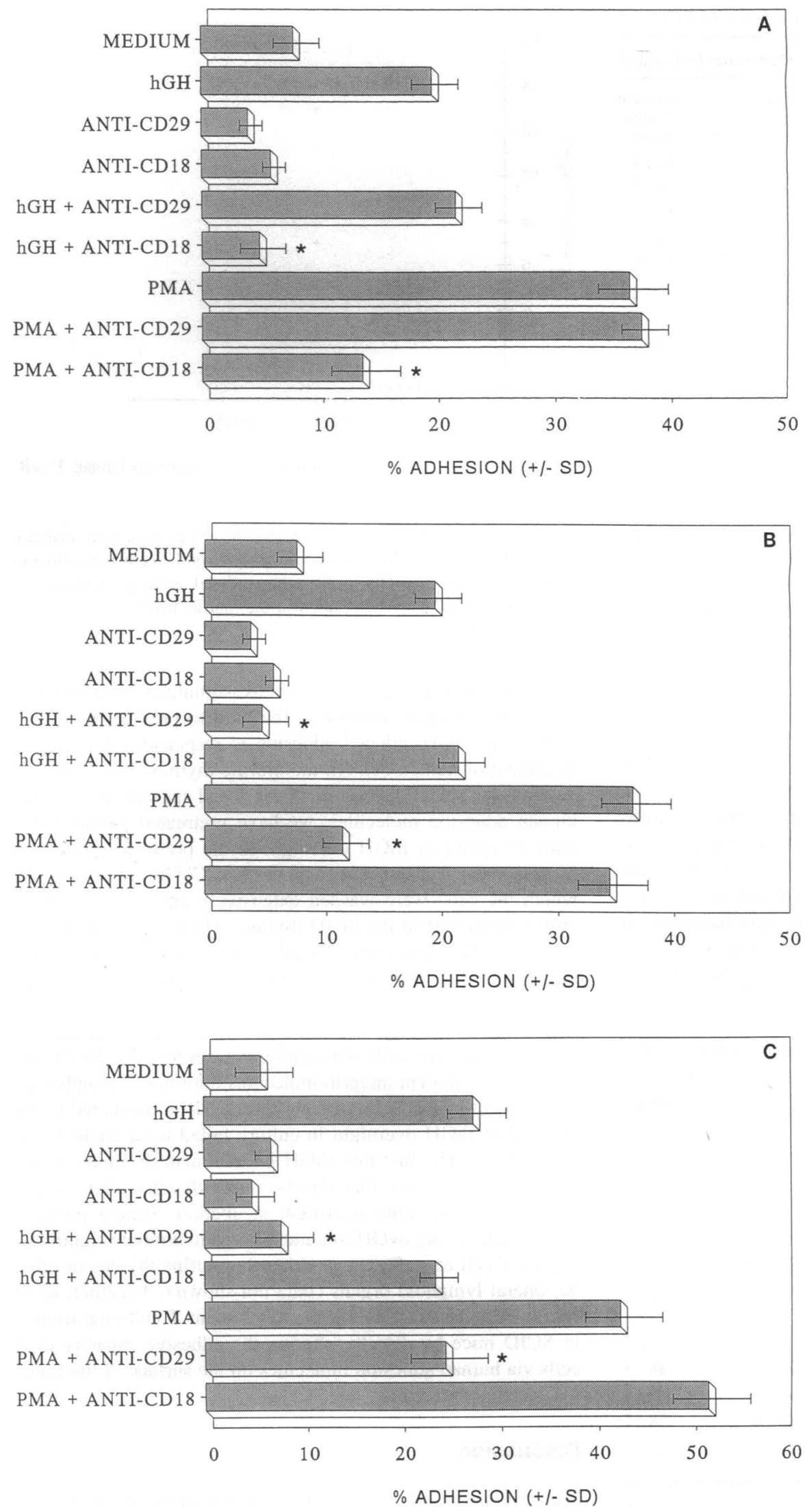

Figure 3. GH-induced $\mathrm{T}$ cell adhesion to immobilized human ICAM-1, VCAM-1, and fibronectin substrates is mediated by integrin molecules. T cells were labeled with chromium-51 and incubated with $20 \mu \mathrm{g} / \mathrm{ml}$ of $\alpha \mathrm{CD} 18$ or $\alpha \mathrm{CD} 29$ antibody for $40 \mathrm{~min}$ on ice. After incubation, the treated $\mathrm{T}$ cells were incubated with various doses of rhGH or PMA for $1 \mathrm{~h}$ on $(A)$ ICAM-1 - , $B$ ) VCAM$1-$, or $(C)$ fibronectin-coated plates. After incubation, nonadherent cells were removed, and the percentage of adherent $T$ cells was quantitated. The results are expressed as percentage of adhesion ( \pm SD) which represents a ratio between counts per minute bound to the plate versus the counts per minute of the total number of $\mathrm{T}$ cells added to each well. $* P<0.05$. 
Table I. GH Induces the Migration of Human T Cells In Vitro

\begin{tabular}{lccc}
\hline & & \multicolumn{2}{c}{ Cells per high power field $(+\overline{\mathrm{SD}})^{*}$} \\
\cline { 3 - 4 } \multicolumn{1}{c}{ Group } & Concentration & $\begin{array}{c}\text { Unstimulated } \\
\text { T cells }\end{array}$ & $\begin{array}{c}\text { Activated } \\
\text { T cells }\end{array}$ \\
\hline Medium & - & $4 \pm 2$ & $11 \pm 4$ \\
rhGH & $1 \mu \mathrm{g} / \mathrm{ml}$ & $32 \pm 9$ & $16 \pm 7$ \\
rhGH & $500 \mathrm{ng} / \mathrm{ml}$ & $23 \pm 11$ & $42 \pm 7$ \\
rhGH & $250 \mathrm{ng} / \mathrm{ml}$ & $35 \pm 7$ & $36 \pm 12$ \\
rhGH & $100 \mathrm{ng} / \mathrm{ml}$ & $18 \pm 5$ & $32 \pm 9$ \\
rhGH & $50 \mathrm{ng} / \mathrm{ml}$ & $3 \pm 1$ & $16 \pm 2$ \\
rhGH & $10 \mathrm{ng} / \mathrm{ml}$ & $6 \pm 2$ & $19 \pm 3$ \\
rhGH & $1 \mathrm{ng} / \mathrm{ml}$ & $10 \pm 6$ & $14 \pm 3$ \\
rhGH & $0.5 \mathrm{ng} / \mathrm{ml}$ & $15 \pm 8$ & $8 \pm 3$ \\
rhGH & $0.1 \mathrm{ng} / \mathrm{ml}$ & $4 \pm 1$ & $22 \pm 16$ \\
RANTES & $10 \mathrm{ng} / \mathrm{ml}$ & $28 \pm 6$ & $46 \pm 9$ \\
RANTES & $1 \mathrm{ng} / \mathrm{ml}$ & $46 \pm 4$ & $65 \pm 15$ \\
RANTES & $0.1 \mathrm{ng} / \mathrm{ml}$ & $8 \pm 3$ & $25 \pm 7$ \\
& & & \\
\hline
\end{tabular}

Purified human T cells were placed in a 48-well microchemotaxis chamber with rhGH at various concentrations on fibronectin-coated filters.

After $4 \mathrm{~h}$ of incubation, the number of migrating cells was assessed by histological examination of this matrix-coated filter. * The results are expressed as the average number of migrating cells per high power field $( \pm S D)$ from a total of 10 high power fields counted.

given $10-\mu \mathrm{g}$ injections of $\mathrm{hGH}$ or ovGH every other day starting the day of huPBL transfer. Then, thymocytes from these mice were analyzed $6 \mathrm{wk}$ after transfer by flow cytometric analysis. As demonstrated previously, rhGH treatment significantly increased both the incidence and extent of human cell engraftment in the rnurine thymus (Fig. 4). The predominant cell type to engraft was $\mathrm{CD}^{+}, \mathrm{HLA}^{+}$lymphocytes $(7,8)$. However, ovGH treatment failed to promote significant human T cell engraftment in either the murine thymus (Fig. 4) or other peripheral lymphoid organs (data not shown). These results suggest that rhGH is directly stimulating human $\mathrm{T}$ cells to promote peripheral engraftment in the murine thymus.

Pretreatment of human $T$ cells with rhGH permits lymphocyte engraftment in the thymus of SCID mice via human $\beta 2$ and $\beta 1$ integrins. While the results in Figs. 1-3 demonstrate

Table II. Checkerboard Analysis of the Effects of rhGH on Human T Cells

\begin{tabular}{rrrcc}
\hline \multirow{2}{*}{$\begin{array}{c}\text { rhGH in } \\
\text { bottom } \\
\text { wells }\end{array}$} & \multicolumn{4}{c}{ rhGH in top wells of chamber $(\mathrm{ng} / \mathrm{ml}) *$} \\
\cline { 2 - 5 } & \multicolumn{1}{c}{0} & 10 & 50 & 100 \\
\hline 0 & $9 \pm 2$ & $11 \pm 3$ & $43 \pm 6$ & $57 \pm 5$ \\
10 & $15 \pm 4$ & $14 \pm 4$ & $35 \pm 7$ & $48 \pm 3$ \\
50 & $38 \pm 4$ & $36 \pm 3$ & $46 \pm 4$ & $49 \pm 4$ \\
100 & $64 \pm 6$ & $53 \pm 5$ & $45 \pm 6$ & $58 \pm 5$ \\
\hline
\end{tabular}

Purified T cells $\left(5 \times 10^{6}\right.$ cells $\left./ \mathrm{ml}\right)$ were tested for their ability to migrate in response to rhGH. Various dilutions of rhGH were placed either in the top and/or bottom wells of a microchemotaxis chamber. * The results are expressed as the number of migrating $\mathrm{T}$ cells per high power field $( \pm \mathrm{SD})$.

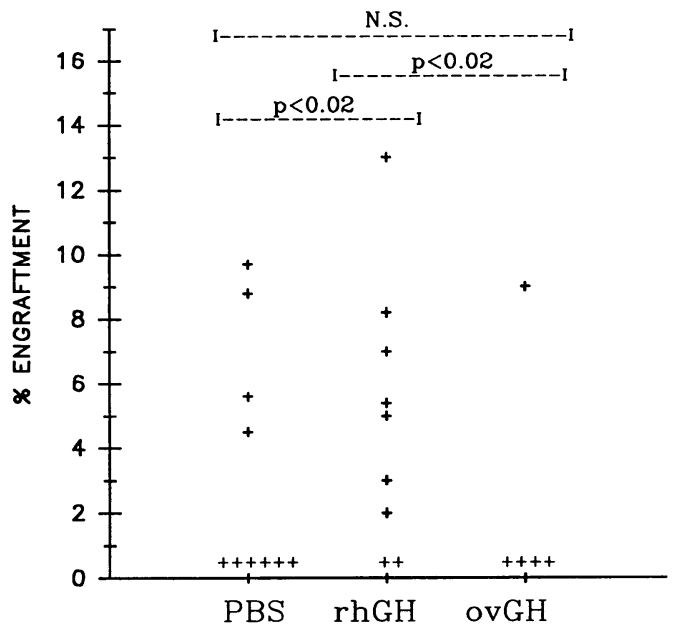

Figure 4. rhGH but not ovGH administration increased human $\mathrm{T}$ cell engraftment in the thymus of SCID mice. SCID mice were given 10$\mu \mathrm{g}$ injections of rhGH or ovGH every other day starting the day of human peripheral blood lymphocyte transfer. Mice were then analyzed $6 \mathrm{wk}$ after transfer by flow cytometric analysis of the cells in the thymus of these treated mice. The results are expressed as the percentage of $\mathrm{CD}^{+}{ }^{+} \mathrm{HLA}-\mathrm{ABC}^{+}$cells engrafted in the murine thymus.

in vitro evidence that rhGH directly stimulates human $\mathrm{T}$ cell adhesion to various substrates, they fail to provide direct evidence that rhGH-induced adhesion is responsible for the engraftment of human cells in the murine thymus. In an effort to determine if rhGH directly mediates $\mathrm{T}$ cell engraftment through human adhesion molecules, we have pretreated human PBLs with $10 \mathrm{ng} / \mathrm{ml}$ of rhGH overnight in the presence or absence of anti-human CD18 and anti-human CD29 antibody, after which the cells were washed extensively and tested for their ability to engraft in the SCID thymus. Thymocytes from these mice were then analyzed $72 \mathrm{~h}$ after PBL transfer by flow cytometric analysis. The results in Fig. 5 demonstrate that rhGH pretreatment significantly increased both the incidence and extent of human cell engraftment in the murine thymus. Preincubation of these same cells with antibodies specific for the $\beta 1$ and $\beta 2$ chains of human integrin molecules inhibited $\mathrm{T}$ lymphocyte engraftment in the SCID thymic tissue. PBLs incubated in the absence of rhGH overnight in culture failed to promote $\mathrm{T}$ cell engraftment. The fact that rhGH pretreatment promotes $T$ cell engraftment suggests that this hormone directly alters $T$ cell adhesion in vitro after overnight incubation. Similar pretreatment studies using ovGH treatment failed to promote significant human $\mathrm{T}$ cell engraftment in either the murine thymus or other peripheral lymphoid organs (data not shown). Together, these results suggest that rhGH promotes human $\mathrm{T}$ cell engraftment in SCID mice by directly altering the adhesive capacity of T cells via human adhesion molecules on the surface of the transferred lymphocytes.

\section{Discussion}

We demonstrate here that rhGH is capable of promoting human $\mathrm{T}$ cell adhesion and migration to both human and murine matrix proteins in vitro and directly affects human $\mathrm{T}$ cell engraftment in SCID mice. GH may induce the expression or activation of 


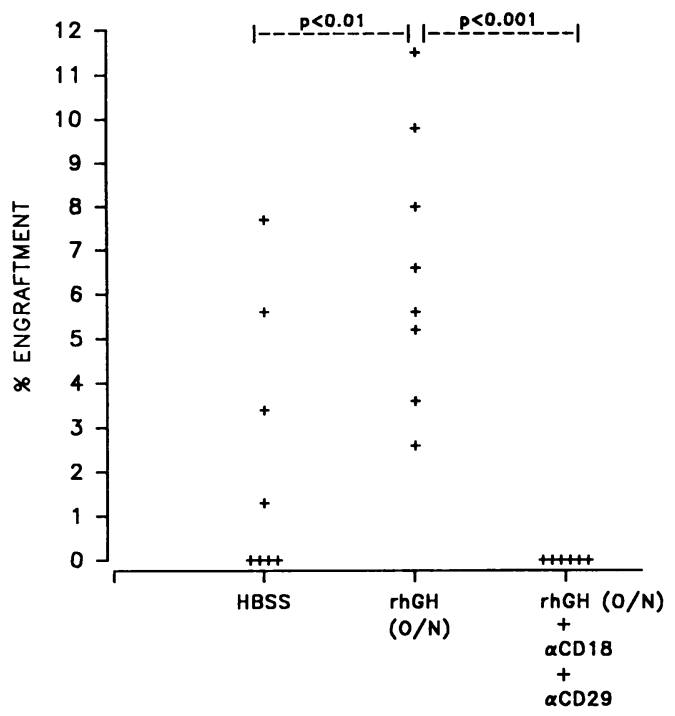

Figure 5. Pretreatment of human T cells with rhGH permits lymphocyte engraftment in the thymus of SCID mice via human $\beta 2$ and $\beta 1$ integrins. Resting T cells were preincubated with $10 \mathrm{ng} / \mathrm{ml}$ of $\mathrm{rGH}$ or PBS overnight in the presence or absence of $10 \mu \mathrm{g} / \mathrm{ml}$ of $\alpha \mathrm{CD} 18$ or $\alpha \mathrm{CD} 29$ antibody, after which the cells were harvested and injected into the peritoneal cavity of SCID mice. Mice were then analyzed $72 \mathrm{~h}$ after transfer by flow cytometric analysis of the human cells in the thymus of these treated mice. The results are expressed as the percentage of $\mathrm{CD}^{+}{ }^{+} \mathrm{HLA}-\mathrm{ABC}^{+}$cells engrafted in the murine thymus.

certain adhesion molecules or homing receptors on the surface of the $\mathrm{T}$ cell, which may permit lymphocyte movement and entry into lymphoid tissues. Although the molecular mechanisms involved in $\mathrm{GH}$ priming of $\mathrm{T}$ cells for enhanced adhesion are not yet defined, the fact that $\mathrm{GH}$ treatment of purified $\mathrm{T}$ cells results in no increase in the cell-surface expression of known adhesion molecules suggests that GH may alter the affinity of adhesion receptors for their respective ligands. This hypothesis seems more likely as an increase in T cell-binding to purified ICAM-1 and VCAM-1 was observed within a 30min period. Similar observations have been made recently with various members of the chemokine superfamily (11). While the ability of rhGH to promote $\mathrm{T}$ cell adhesion is highly supportive, it fails to provide direct evidence that the in vitro changes in $\mathrm{T}$ cell adhesion are responsible for enhanced $\mathrm{T}$ cell engraftment in the SCID thymus. The pretreatment and neutralization studies in Fig. 5 demonstrate that rhGH affects human $\mathrm{T}$ cells directly by altering lymphocyte adhesion to various substrates in vitro and by promoting $\mathrm{T}$ cell engraftment in vivo. These GH-mediated interactions require the presence of active human $\beta 2$ and $\beta 1$ integrin molecules on the $\mathrm{T}$ cell surface. While these data are highly suggestive, a direct quantitation of changes in the affinity of integrin receptors after GH treatment has not yet been performed.

Our finding that $\mathrm{GH}$ is capable of inducing $\mathrm{T}$ lymphocyte migration was quite unexpected. However, a recent report has described the ability of rhGH to stimulate human monocyte chemotaxis in vitro (13). Our initial studies were performed in an effort to assess ability of GH to facilitate $\mathrm{T}$ cell migration on various extracellular matrix proteins. Surprisingly, GH induced $\mathrm{T}$ cell locomotion at concentrations as low as $0.1 \mu \mathrm{g} / \mathrm{ml}$ on both fibronectin- and collagen-coated filters. No migration was observed on noncoated polycarbonate chemotaxis filters, suggesting that cellular adhesion to matrix molecules plays an important role in $\mathrm{GH}$-induced migration. As positive controls, the $\beta$ chemokines MIP- $\beta$ and RANTES were also used in the adhesion and migration assays. RANTES has been shown previously to induce the directional migration and adhesion of both resting $\mathrm{CD}^{+}$and activated $\mathrm{CD}^{+}$and $\mathrm{CD} 8^{+} \mathrm{T}$ cells in vitro (10). Similarly, MIP-1 $\beta$ preferentially induces the adhesion and migration of activated $\mathrm{CD}^{+} \mathrm{T}$ lymphocytes (10). However, preliminary data suggest that GH increases only random movement rather than the directional migration of both $\mathrm{CD}^{+}$and $\mathrm{CD}^{+} \mathrm{T}$ cells. Random migration or chemokinesis is thought to be an important mechanism by which cells move within a given lymphoid tissue after cellular activation. The fact that $\mathrm{GH}$ also augments $\mathrm{T}$ cell adhesion to extracellular matrix proteins suggests that this hormone may enable $\mathrm{T}$ cells to bind and randomly migrate on various substrates via their "activated" integrin molecules within a tissue. Cellular migration into the various compartments within a lymphoid organ plays an important role in $\mathrm{T}$ cell activation by antigen-presenting cells and B cell activation and expansion through interaction with $\mathrm{T}$ cells as well as in the education of developing $\mathrm{T}$ cells within the thymus. We have demonstrated previously that rhGH treatment increases $\mathrm{T}$ cell progenitor development in mice deficient in $\mathrm{GH}(5,6)$. The chemokinetic role of $\mathrm{GH}$ in facilitating immune responses and thymic development in vivo is currently under investigation.

Thus, GH is capable of promoting human $\mathrm{T}$ cell adhesion and migration in vitro, which may be the mechanism underlying the effects of rhGH on human T cell engraftment in SCID mice. The data presented here demonstrate that there is also sufficient homology between human and murine adhesion molecules to permit productive xenogeneic interactions, both in vitro and in vivo. These results also suggest that rhGH may be of potential clinical use to promote $T$ cell development and recirculation in instances of $\mathrm{T}$ cell deficiencies.

\section{Acknowledgments}

We thank Christie L. Harrison, Kelli Taylor, and the Clinical Monitoring Laboratory for excellent technical assistance. We also thank Terry Phillips for superb secretarial services.

\section{References}

1. van Buul-Offers, S., and J. L. Van den Brande. 1981. The growth of different organs of normal and dwarfed Snell mice, before and during growth hormone therapy. Acta Endocrinol. 96:46-58.

2. D'Ercole, A. J., A. D. Stiles, and L. E. Underwood. 1984. Tissue concentrations of somatomedin $\mathrm{C}$ : further evidence for multiple sites of synthesis and paracrine or autocrine mechanisms of action. Proc. Natl. Acad. Sci. USA. 81:935939.

3. Kelley, K. W. 1989. Commentary. Growth hormone, lymphocytes and macrophages. Biochem. Pharmacol. 38:705-713.

4. Snow, E. C., T. L. Feldbush, and J. A. Oaks. 1981. The effect of growth hormone and insulin upon MLC responses and the generation of cytotoxic lymphocytes. J. Immunol. 126:161-164.

5. Murphy, W. J., S. K. Durum, and D. L. Longo. 1993. Differential effects of growth hormone and prolactin on murine T cell development and function. $J$. Exp. Med. 178:231-236.

6. Murphy, W. J., S. K. Durum, and D. L. Longo. 1992. Role of neuroendocrine hormones in murine $\mathrm{T}$ cell development. Growth hormone exerts thymopoietic effects in vivo. J. Immunol. 149:3851-3857.

7. Murphy, W. J., S. K. Durum, and D. L. Longo. 1992. Human growth 
hormone promotes engraftment of murine or human $\mathrm{T}$ cells in severe combined immunodeficient mice. Proc. Natl. Acad. Sci. USA. 89:4481-4485.

8. Murphy, W. J., S. K. Durum, M. Anver, M. Frazier, and D. L. Longo. 1992. Recombinant human growth hormone promotes human lymphocyte engraftment in immunodeficient mice and results in an increased incidence of human Epstein Barr Virus-induced B-cell lymphoma. Brain Behav. Immun. 6:355-364.

9. Murphy, W. J., M. Bennett, M. R. Anver, M. Baseler, and D. L. Longo. 1992. Human-mouse lymphoid chimeras: host-vs.-graft and graft-vs.-host reactions. Eur. J. Immunol. 22:1421-1427.

10. Taub, D. D., K. Conlon, A. R. Lloyd, J. J. Oppenheim, and D. J. Kelvin.
1993. Preferential migration of activated $\mathrm{CD}^{+}{ }^{+}$and $\mathrm{CD} 8^{+} \mathrm{T}$ cells in response to MIP- $1 \alpha$ and MIP-1 $\beta$. Science (Wash. DC). 260:355-358.

11. Oppenheim, J. J., C. O. C. Zachariae, N. Mukaida, and K. Matsushima. 1991. Properties of the novel proinflammatory supergene "intercrine" cytokine family. Annu. Rev. Immunol. 9:617-648.

12. Rui, H., Y. J. Djeu, G. A. Evans, P. A. Kelly, and W. L. Farrar. 1992. Prolactin receptor triggering. Evidence for rapid tyrosine kinase activation. $J$. Biol. Chem. 267:24067-24081.

13. Wiedermann, C. J., N. Reinisch, and H. Braunsteiner. 1993. Stimulation of monocyte chemotaxis by human growth hormone and its deactivation by somatostatin. Blood. 82:954-960. 